\title{
Policy and Practice in Standards Selection for E-Government Interoperability Frameworks
}

\author{
Luis Guijarro \\ Communications Department, Polytechnic University of Valencia, \\ Camino de Vera, s/n, 46022 Valencia, Spain \\ lguijar@dcom.upv.es
}

\begin{abstract}
Interoperability has been identified as a major issue to be addressed by every e-government agency. An interoperability framework aims to provide the basic standards that every department which is relevant for the e-government strategy implementation should adopt. Criteria for selection and inclusion of standards in an interoperability framework are crucial, since they influence the utility that the framework delivers to the e-government agencies. This paper identifies and compares the policies of the main e-government agencies in the definition of these criteria and it checks the policies against the practice that they exhibit in the actual interoperability frameworks.
\end{abstract}

\section{Introduction}

During late 90s, most administrations in OECD countries released their egovernment strategies. Each e-government strategy is supported by its own framework policies, covering security, confidentiality, delivery channels, etc. One of such policies is the interoperability framework [6], [18].

Interoperability between computing components may be generally defined as "the ability to exchange information and mutually to use the information which has been exchanged" [5]. An interoperability framework aims to provide the basic standards that every department which is relevant for the e-government strategy implementation should adopt. This interoperability framework should enable, at least, the interoperability between information systems from different agencies in order to provide services to citizens and businesses in an integrated way.

In this paper the most known interoperability frameworks are presented. After that, the criteria that determine whether a standard is eligible for the framework are described. These criteria are studied from two perspectives: that of the policy statement, and that of the practice. Finally, some conclusions are formulated.

This work is part of a research on the use and utility of the interoperability frameworks for e-government, which is being conducted by the author, and the first results of which were published in Cava (2003) and Guijarro (2004). The research kicked-off within the E-Forum Association ${ }^{1}$. From January until September 2003, the Shared Infrastructures Working Group carried out an study of the

\footnotetext{
1 Visit http://www.eu-forum.org

M.A. Wimmer et al. (Eds.): EGOV 2005, LNCS 3591, pp. 163-173, 2005.

(C) Springer-Verlag Berlin Heidelberg 2005
} 
interoperability issues of the shared infrastructures that support the delivery of egovernment services. Furthermore, since January 2004, a research has being coordinated by the author to analyse the e-government initiative of the Regional Government of Valencia from the strategic and technical viewpoints, and an interoperability framework is currently being generated within the Telecommunications and Information Society Department of the Regional Government of Valencia ${ }^{2}$.

\section{Interoperability Frameworks}

In this section, five of the major initiatives being carried out by e-government agencies in the interoperability arena, which have produced corresponding interoperability frameworks, are briefly described.

The e-Government Unit ${ }^{3}$, formerly known as Office of the e-Envoy, in the UK has based its technical guidance in the e-Government Interoperability Framework (e-GIF), which was issued in 2000, and updated to its version 6.0 in April 2004. e-GIF mandates sets of specifications and policies for joined-up and web enabled government. It covers four areas: interconnectivity, data integration, e-services access and content management [10].

The French ADAE", formerly known as ATICA, published "Le Cadre Commun d'Intéroperabilité" (CCI) in January 2002 and its last version (2.1) in September 2003. CCI comprises the recommendations for strengthening public electronic systems coherence and for enabling multi-agency electronic service delivery [1].

The Federal Government Coordination and Advisory Agency for IT in the Federal Administration (KBSt) ${ }^{5}$ in Germany, published the Standards and Architectures for e-Government Applications (SAGA) in February 2003, and updated to its version 2.0 in December 2003. SAGA, which stems from the BundOnline 2005 e-government initiative launched in September 2000, is a guideline that serves as an orientation aid for decision-makers in the e-government teams in German administrations [16].

The European Commission Enterprise and Industry Directorate-General, through the IDABC Program ${ }^{6}$, issued its Architecture Guidelines (version 4.1) in March 1999, as a supporting tool for the Decision of the European Parliament and the Council 1720/1999/EC "Interoperability and access to Trans-European Networks for the electronic Interchange of Data between Administrations". Current version is 7.1 and it was issued in September 2004 [14]. These guidelines (hereafter IDABC AG) provide concepts and reference for optimum interoperability between European Institutions, European Agencies, and Administrations in member States. Furthermore, IDABC published the final version 1.0 of its European Interop-

\footnotetext{
${ }^{2}$ Visit http://www.avantic.es

${ }^{3}$ Visit http://www.cabinetoffice.gov.uk/e-government/

4 "Agence pour le Développement de l'Administration Électronique". Visit http://www.adae.gouv.fr/

${ }^{5}$ Visit http://www.kbst.bund.de/

${ }^{6}$ Interoperable Delivery of European eGovernment Services to public Administrations, Business and Citizens - IDABC. Visit http://europa.eu.int/idabc/
} 
erability Framework (IDABC EIF) in November 2004 [15]. This document provides a common framework for discussion around interoperability, pinpointing which interoperability issues should be addressed when implementing pan-European eGovernment services, but it avoids prescribing any concrete Architecture Framework, which was to be the main objective of successive releases of IDABC AG.

Finally, the Federal Chief Information Officers (CIO) Council ${ }^{7}$, in the USA, issued the Federal Enterprise Architecture Framework (FEAF) in September 1999 [7], and published its second version of the E-Gov Enterprise Architecture Guidance (CIOC EAG) in July 2002, for guiding the e-government initiatives financed by the President's Office [8].

\section{Standards Development Organisations}

When dealing with standardisation, controversy arises when attempting to classify the myriad standardisation organisations, which we will call Standards Development Organisations (SDOs) hereafter.

Following Egyedi (2001), a distinction can be made between formal standards bodies and standards consortia. Regarding the first ones, "formal standardisation refers to the voluntary consensus standards processes that take place in technical committees under the auspices of national, regional (e.g. European), and international standards bodies. The procedures that govern these committees express democratic values, aim to be inclusive and reflect the desirability of a technical and politically neutral standards process (e.g. in the approval stage of a standard only the negative votes which are accompanied by technical arguments are counted)." Examples of these bodies are $\mathrm{ISO}^{8}$, ITU ${ }^{9}$ and ETSI ${ }^{10}$. On the other hand, a standards consortium, examples of which have emerged in the field of information and communication technologies with high market relevance, is defined as "an alliance of firms and organisations, financed by membership fees, formed for the purpose of coordinating technology development and/or implementation activities. Its outcomes are publicly available, multi-party industry specifications or standards. Usually its members are large companies, which indicates that the resulting standards are likely to be very relevant for the market. These consortia are also referred to as market-driven consortia." Examples of these consortia are the $\mathrm{IETF}^{11}$, the $\mathrm{W}_{3} \mathrm{C}^{12}$, and $\mathrm{OASIS}^{13}$.

\footnotetext{
7 Visit http://www.cio.gov

${ }^{8}$ Visit http://www.iso.org

9 Visit http://www.itu.int

${ }^{10}$ Visit http://www.etsi.org

11 The IETF is the protocol engineering and development arm of the Internet. Though it existed informally for some time, the group was formally established in 1986. (taken from http://www.ietf.org)

12 Tim Berners-Lee and others created W3C as an industry consortium dedicated to building consensus around Web technologies. (taken from http://www.w3.org)

13 OASIS (Organization for the Advancement of Structured Information Standards) is a not-for-profit, international consortium that drives the development, convergence, and adoption of e-business standards. (taken from http://www.oasis-open.org)
} 
Apart from the above SDOs, several companies perform activities aimed at creating communities of interests around their proprietary technologies and emulate standardisation procedures. Such is the case of Sun's Java Community Process $(\mathrm{JCP})^{14}$, which has succeeded in involving other companies and individuals in developing and implementing the Java platform.

\section{Policy Principles for Standards Selection in Interoperability Frameworks}

In this section, the main documents that describe the interoperability frameworks are analysed. The purpose of the analysis is to identify the principles that each e-government initiative has setup for steering the selection of the standards to be included in the interoperability framework.

\subsection{General Criteria}

Each interoperability framework stresses in a particular way the required characteristics for a standard to be included in the interoperability framework.

In e-GIF 6.0 the selection of specifications has been driven by [10]:

- interoperability

- market support - the specifications selected are widely supported by the market, and are likely to reduce the cost and risk of government information systems

- scalability

- openness - the specifications are documented and available to the public

- international standards - preference will be given to standards with the broadest remit, so appropriate international standards will take preference over EU standards, and EU standards will take preference over UK standards

The French ADAE, following the recommendations of the e-Government Conference held in Como, Italy, in July 2003, has included an ambiguous support for open standards in the e-Government Strategic Plan, under the ADELE Program, which states that "The aim of the French government is not to impose systematic recourse to free software and open standards in the administration, but to ensure that the whole offer - including the part based on free software - is taken into account at the moment of choice, while interoperability and mutualisation must remain the founding principles of this choice." [2]

The German KBSt fixes a strong basis for the selection of standards when it states that "SAGA pursues the following aims:

1. To ensure ongoing flows of information between citizens, the Federal Government and its partners (interoperability)

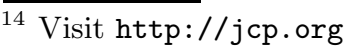


2. To establish comparable procedures for the provision of services and for the definition of data models (re-usability). Federal-state governments and communal administrations have the opportunity to make use of the development results of the BundOnline 2005 initiative.

3. To provide specifications in the form of publicly accessible documentation (openness)

4. To consider developments on the market and in the field of standardization (cost and risk reduction)

5. To ensure the applicability of solutions against the background of changing requirements in terms of volume and transaction frequencies (scalability)" [16]

However, when the concrete procedure for standard evaluation is described, it simply states that "The Federal Ministry of the Interior proposes the standards and architectures which are to be generally adopted for e-government in Germany. This proposal is based on contributions by and annotations from the SAGA forums, the evaluation by the expert commission and the final draft by the authors. The Federal Ministry is subsequently responsible for co-ordination with the Federal departments." [16]

The European Commission, through the IDABC Programme, has published the following guidelines. In 2002, IDABC AG 6.1 established that "it is the general IDA recommendation that IT systems should be based on:

- Formal European and International Standards

- Standards originated in the Internet World via the work of the IETF and W3C

- Relevant other wider adopted information IT specifications in the public domain, referred to as Publicly Available Specifications (PAS). A PAS is a specification that meets certain criteria making it suitable for processing as an ISO/IEC International Standard." [13]

Furthermore, in the IDABC EIF states that one of its basic principles is the use of open standards [15]. The current version of IDABC AG (7.1) has been modified and it endorses the EIF principles. The issue of open standards enforcement is dealt more deeply in the following section.

Finally, the CIOC states that "The FEAF principles are summarized here in order to emphasize their applicability and importance to this E-Gov guidance" [13]. One of the FEAF principles is as follows: "The Federal Government should adopt open system ["voluntary industry" in [13]] standards in which the interrelationships of components are fully defined by interface standards available to the public and maintained by group consensus. The Federal Government should adopt, acquire, and integrate those components that conform to specification. An open system ["non-proprietary" in [13]] architecture is the goal; however, initially partially open ["compliant" in [13]] systems will be attained. This principles could lead to use of JAVA and future JAVA-like protocols, which give a high priority to platform independence. The Federal Government should be able to ensure compliance with these standards" [7]. Note the change of some terms from CIOC (1999) to CIOC (2002). 
Although the CIOC principles may seem ambiguous, the Office of Management and Budget of the President of the USA (OMB) issued a circular [19] which clearly states the policy in this subject. The circular states that "all federal agencies must use voluntary consensus standards in lieu of government-unique standards in their procurement and regulatory activities, except where inconsistent with law or otherwise impractical".

\subsection{Open Standards Enforcement Policy}

As the previous analysis shows, different requirements are put over a candidate technology to be included in the interoperability framework. On one hand, the UK e-Government Unit and the German KBSt only require that technical specifications should be open. On the other, the IDABC EIF explicitly requires that the adopted standards should be qualified as "open standard", and the USA OMB requires that they should be "voluntary consensus standards".

The fact that a specification should be open only requires that it should be publicly available. On the other hand, when a standard is said to be open, more requirements are meant to be met.

There is not a unanimously agreed definition of "open standard". One of the earliest definitions was provided by the IEEE 1003.1 - 1988 POSIX standard, where "open specifications" are "specifications that are maintained by an organisation that uses an open, public consensus process to accommodate new technologies and user requirements over time".

The ICT Industry, through the Computing Technology Industry Association (CompTIA), puts forward the following definition: "An Open Standard can be seen as a set of rules and specifications that collectively describe the design or operating characteristics of a programme or device and is published and made freely available to the technical community. Open standards are vetted through an open process." [9].

The OMB goes further inside the subject of the standardisation process and uses the term "voluntary consensus standards", which are defined [19] as "standards developed or adopted by voluntary consensus standards bodies, both domestic and international. A voluntary consensus standards body is defined by the following attributes:

- openness;

- balance of interest;

- due process;

- an appeal process;

- and consensus, which is defined as general agreement, but not necessarily unanimity, and which includes a process for attempting to resolve objections by interested parties, as long as all comments have been fairly considered, each objector is advised of the disposition of his of her objection(s) and the reasons why, and the consensus body members are given an opportunity to change their votes after reviewing the comments" 
On the other hand, non-consensus standards, industry standards, company standards or de facto standards, are developed in the private sector but not in the full consensus process.

The above attributes match the principles used by ANSI for accrediting SDOs in the USA [3], such as the EIA (Electronics Industries Alliance) and the TIA (Telecommunications Industries Alliance).

The IDABC "open standard" definition that is contained in EIF is taken from the Open Standards and Open Source Software in Government (OSOSS) Programme ${ }^{15}$, financed by the Dutch Government. It defines open standards as those ones meeting the following requirements:

1. The standard is adopted and will be maintained by a not-for-profit organisation, and its ongoing development occurs on the basis of an open decisionmaking procedure available to all interested parties (consensus or majority decision etc.);

2. The standard has been published and the standard specification document is available either freely or at a nominal charge. It must be permissible to all to copy, distribute and use it for no fee or at a nominal fee;

3. Intellectual property - i.e. patents possibly present - of (parts of) the standard is irrevocably made available on a royalty-free basis;

4. There are no constraints on the re-use of the standard.

The definition has raised controversy among the ICT industry in Europe, which points out that any "open standard" definition - and specially the EIF definition - should be carefully assessed as to the impact such definition will necessarily have on the different stakeholders, including the computing industry in general" [9]. CompTIA is specially worried about the impact on the public procurement practices, which may not observe of the principles of nondiscrimination and equal treatment, which underlie the EU public procurement policy. Furthermore, CompTIA is afraid that "defining open standards in a way that excludes standards including royalty-bearing technology held by commercial entities in fact would force such intellectual property rights holders to give up their rights which would amount to an indirect expropriation" [9]. This issue is subject to consideration in the following section.

\subsection{Intellectual Property Rights and Standards}

Intellectual Property Rights (IPR), which includes both copyright and patents, are an important issue in standardisation, and therefore when standard selection criteria is at stake. As it has been shown in the previous section, among the interoperability frameworks under study, it is the IDABC EIF, the one that explicitly regards the IPR as an issue ${ }^{16}$.

\footnotetext{
$\overline{15}$ Visit http://www.ososs.nl

16 There are however definitions of "open standards", not linked to interoperability frameworks, that also include IPR disclosure. See, for example, Oregon House Bill 2892.
} 
When dealing with IPR inside the standardisation procedures, two license agreements are commonly referred to, which describe the terms to which a patent contributor to a standard must (or may) adhere to:

- Royalty-free (RF) basis

- Reasonable and non-discriminatory (RAND) basis. Under RAND licensing, if a technology that is part of the standard is to be licensed for a fee, the terms must be nonexorbitant, published, and the same for all implementers (rather than subject to individual negotiation).

Each SDO establishes its own IPR policy, but some common features can be identified:

- The Formal Technical Standards Organisations (TSO), such as ISO, ITU and ANSI, usually establish that "where essential technology is patented, a patentee can be asked for a declaration that it is willing to license on RF or RAND terms", and, "if this is not forthcoming or the patentee does not wish to be involved in the standardization process at all, the TSO is encouraged '... to seek an alternative approach" [17]

- Standards consortia show diverse policies. W3C "seeks to issue Recommendations that can be implemented on a RF basis. Subject to the conditions of this policy, W3C will not approve a Recommendation if it is aware that essential claims exist which are not available on RF terms." [20] whereas RAND is perfectly permissible under the ATM Forum rules.

Once light has been shed on the IPR Policy of the SDOs, it can be concluded that IDABC is pressing towards an scenario where not only proprietary specifications are discouraged, but also those standards that, even following open processes, do not exhibit an RF licensing policy. In CompTIA's [9] opinion, "such would be contrary to the overall policy of the [European] Commission to strengthen IPR protection, but would moreover be found contrary to the EU's obligations under the WTO Agreement on Trade-related Intellectual Property Rights (TRIPS Agreement)".

\section{Practice in Standards Selection for Interoperability Frameworks}

In this section, the above policies are checked against the practice that each egovernment agency exhibit. Documents that are published by the e-government agencies are again the source for the analysis of their practice. The documents we are interested on are technical catalogues which enumerates the standards included in the interoperability framework. These catalogues are usually provided as annexes to the core documents that state the policy. It is not the intent of the analysis to identify all possible standards and SDOs applicable to the interoperability frameworks, nor to create even a comprehensive set. The aim of the 
analysis is to illustrate how much alignment the e-government agencies enforce between their policies and their practice.

The analysis traced a limited set of technologies, specifications and standards from different SDOs, both TSOs and standards consortia. These technologies, specifications and standards are the following: IPv4, HTTP or SNMP from the IETF; XML and WSDL from the W3C; SAML from OASIS; J2EE from the JCP; RTF and .NET from Microsoft; PDF from Adobe; and JPEG from the ISO.

The results of the analysis were the following ones:

- In the UK e-GIF 6, IPv4, WSDL, SAML, RTF, PDF and JPEG has the status of "adopted", which is the highest one in the e-GIF (lower status are "recommended", "under review", and "for future consideration").

- In the ADAE CCI, IPv4, SAML, RTF, PDF and JPEG have the status of "applicable", whereas SAML is shown as "candidate".

- In the KBSt SAGA, IPv4, WSDL, PDF and JPEG have the status of "mandatory", no reference is made to RTF, but WMV is shown as "under observation". On the other hand, J2EE 1.4 is "mandatory", whereas .NET is kept "under observation". The status grades in SAGA are "mandatory", "recommended", and "under observation".

- In IDABC AG, IPv4, HTTP, XML, and PDF, have the status of "mandatory"; SAML, J2EE, RTF, and JPEG have the status of "recommended", and WSDL is "under consideration". The status grades in AG are the same as in SAGA.

- Finally, in CIOC EAG, SMTP, WSDL, SAML, J2EE, and .NET are included, but no reference to data format standards is made.

From the above results, some issues may be pointed out:

- The IETF, W3C and OASIS are regarded as reference standardisation bodies by the five e-government agencies under study.

- When document formatting is an issue in the interoperability framework, which is the case for e-GIF, CCI, SAGA and AG, both open standards and proprietary de facto standards are selected, as it is the case for PDF from Adobe and RTF from Microsoft.

- When application platforms is an issue in the interoperability framework, which is the case for SAGA, AG and EAG, J2EE is always selected but some interoperability frameworks do not assign the same level of recognition to .NET.

\section{Conclusions}

The e-government agencies policy and practice have been scrutinized in order to clarify the criteria for the selection and adoption of standards in their interoperability frameworks. The study has been based on the analysis of the publicly available documents. 
From the policy viewpoint, it has been identified a clear commitment in egovernment agencies to enforce the use of open standards. There is no unanimity, however, in the set of requirements that a standard must fulfil in order to be qualified as open standard. The European Commission, through the IDABC Programme, is pushing for the most ambitious set of requirements, although this strategy is facing the opposition of the ICT industry.

In the practice arena, nevertheless, the common practice is that open standards are adopted, but also specifications and proprietary technologies are used in e-government de facto implementations. We strongly believe that the adoption of the latter has been driven by the existing gap in areas such as document formatting and application architectures, where de facto standards have seized the market.

\section{Acknowledgements}

This work has been supported by the Company, University and Science Department of the Valencian Government, through the R+D Project GV04A-414.

\section{References}

1. ADAE (2003), Le Cadre Commun d'Intéroperabilité version 2.1 (http:// www . adae.gouv.fr/article.php3?id_article=219, visited 3/3/2005)

2. ADAE (2004) The e?Government Strategic Plan 2004?2007 (http://www.adae. gouv.fr/article.php3?id_article=315, visited 3/3/2005)

3. ANSI (2000), National Standards Strategy for the United States.

4. Cava, I. \& Guijarro, L. (2003), Interoperability issues of shared infrastructures for e-government, in Proc. of EGOV 2003 Conference, pp. 369-372, Prague.

5. CEC. Commission of the European Communities (1991), Council Directive 91/250/EEC of 14 May 1991 on the legal protection of computer programs.

6. CEC. Commission of the European Communities (2002), eEurope 2005: An information society for all. An Action Plan to be presented in view of the Sevilla European Council, 21/22 June 2002, COM (2002) 263 final.

7. CIOC. Federal Chief Information Officer Council (1999), Federal Enterprise Architecture Framework, version 1.1.

8. CIOC. Federal Chief Information Officer Council (2002), E-Gov Enterprise Architecture Guidance, draft-version 2.0.

9. CompTIA (2004), European Interoperability Framework - ICT Industry Recommendation. White Paper. 18 February, Brussels.

10. e-Gov Unit (2004), e-Government Interoperability Framework, version 6.0.

11. Egyedi, T.M. (2001), Beyond Consortia, Beyond Standardisation? New Case Material and Policy Threads. Final Report for the European Commission. Delft. The Netherlands.

12. Guijarro, L. (2004), Analysis of the interoperability frameworks in e?government initiatives, in Proc. of EGOV 2004 Conference, pp. 36-39, Zaragoza.

13. IDABC. Enterprise DG (2002), Architecture Guidelines for trans-European Telematics Networks for Administrations, version 6.1, Brussels. 
14. IDABC. Enterprise \& Industry DG (2004a), Architecture Guidelines for transEuropean Telematics Networks for Administrations, version 7.1, Brussels.

15. IDABC. Enterprise \& Industry DG (2004b), European Interoperability Framework for pan-European e?government services, version 1.0, Brussels.

16. KBSt (2003), Standards and Architectures for e-Government Applications, version 2.0. (http://www.kbst.bund.de/SAGA, visited 11/3/2005)

17. Marasco, A., (2004) IPR and standards. ANSI. (http://www . incits .org/tc_home/ $\mathrm{m} 1 \mathrm{htm} /$ docs/m1040063.pdf, visited 4/3/2005)

18. OECD, Organisation for Economic Co-operation and Development (2003), The e-Government Imperative, OECD e-Government Studies, France.

19. OMB (1998), Federal participation in the development and use of voluntary consensus standards and in conformity assessment activities, Revised OMB Circular No. A-119.

20. WWW Consortium (2004), W3C Patent Policy, 5 February. 